\title{
A Rare Presentation of Cardiac Aspergilloma in an Immunocompetent Host: Case Report and Literature Review
}

\author{
Abdullah M. Pervaiz ${ }^{1}$, Salman A. Bangash ${ }^{2}$, Raheel Akhtar ${ }^{3}$, Zain Wahab ${ }^{4}$, Hyder Bangash ${ }^{5}$ \\ 1. Internal Medicine, University of Massachusetts Medical School - Baystate Medical Center, Springfield, USA 2. \\ Internal Medicine, Doctors Hospital / University of Texas Rio Grande Valley, Edinburg, USA 3. Internal Medicine, \\ Windsor University School of Medicine, Basseterre, KNA 4. Internal Medicine, Kingsbrook Jewish Medical Center, New \\ York, USA 5. Psychology, The University of Texas at Austin, Austin, USA
}

Corresponding author: Abdullah M. Pervaiz, abdullah.pervaizmd@baystatehealth.org

\begin{abstract}
Cardiac aspergilloma is exceptionally rare with only a handful of cases reported and majority of them being in immunocompromised patients. Here, we present a case of cardiac aspergilloma involving the right and left ventricle in an immunocompetent patient that initially presented with acute limb ischemia. He was later found to have a cardiac mass with histopathological diagnosis confirming Aspergillus species. Despite aggressive medical and surgical interventions, the patient had an unfavorable outcome due to low suspicion of invasive fungal endocarditis given his immunocompetent status. Cardiac aspergilloma should remain in the differential diagnosis of immunocompetent patients as early clinical suspicion will result in early treatment and decreased mortality. Novel therapies are required to decrease mortality in the future from this fatal disease.
\end{abstract}

Received 05/17/2019

Review began 05/25/2019 Review ended 05/26/2019 Published 05/30/2019

๑) Copyright 2019 Pervaiz et al. This is an open access article distributed under the terms of the Creative Commons Attribution License CC-BY 3.0., which permits unrestricted use, distribution, and reproduction in any medium, provided the original author and source are credited.
Categories: Cardiac/Thoracic/Vascular Surgery, Cardiology, Infectious Disease

Keywords: aspergilloma, cardiac aspergilloma, infective endocarditis, aspergillus, immunocompetent, cerebral emboli

\section{Introduction}

Aspergillus is a common fungus that is present in the environment and is known to cause fatal disease, particularly in immunocompromised hosts. Fungal endocarditis is rare and accounts for $<2 \%$ documented cases of infective endocarditis of which only 20-25\% are caused by aspergillus species [1]. Invasive aspergillus involving heart valves and cardiac chambers is exceptionally rare with only a handful of cases reported and majority of them being in immunocompromised patients. Here, we present a case of cardiac aspergilloma involving the right and left ventricle in an immunocompetent patient that initially presented with acute limb ischemia.

\section{Case Presentation}

A 19-year-old male with no known past medical history presented to the hospital with a two-day history of right-sided leg pain with yellowish to bluish discoloration. The patient was tachycardic, normotensive, and afebrile. On examination, he was found to have a cool right lower extremity, delayed capillary refill, and diminished femoral, popliteal, posterior tibial, and dorsalis pedis pulses. The patient had a normal appearance of the contralateral extremity with palpable pulses. On auscultation of his heart, he did not have any murmurs, rubs, or gallops. No focal neurological deficits were appreciated on examination. Laboratory workup revealed a normal complete blood picture and comprehensive metabolic panel, erythrocyte sedimentation rate 115 , c-reactive protein 13.5 , procalcitonin 0.518 , and negative serology for HIV, hepatitis $\mathrm{B}$, and C. Autoimmune workup with antinuclear antibody (ANA), anti-double stranded DNA (dsDNA), complement C3/C4, and antiphospholipid antibodies was also negative. Electrocardiogram showed sinus tachycardia without acute ischemic changes. Chest X-ray did not show an acute cardiopulmonary process. Bilateral arterial and venous dopplers were done which showed a thrombus in the right femoral artery.

The patient was taken to the operating room and successfully underwent right femoral embolectomy for acute limb ischemia. On the first postoperative day, the patient developed blurry vision in his left eye. A CT head without contrast showed no evidence of acute intracranial pathology. Due to concerns for cardiac source of systemic embolization a transthoracic echocardiogram (TTE) was done which showed a $12 \times 10$ $\mathrm{mm}$ mass hanging from the sub-aortic septum extending into the left ventricular outflow tract (LVOT) (Figure 1). 


\section{Cureus}

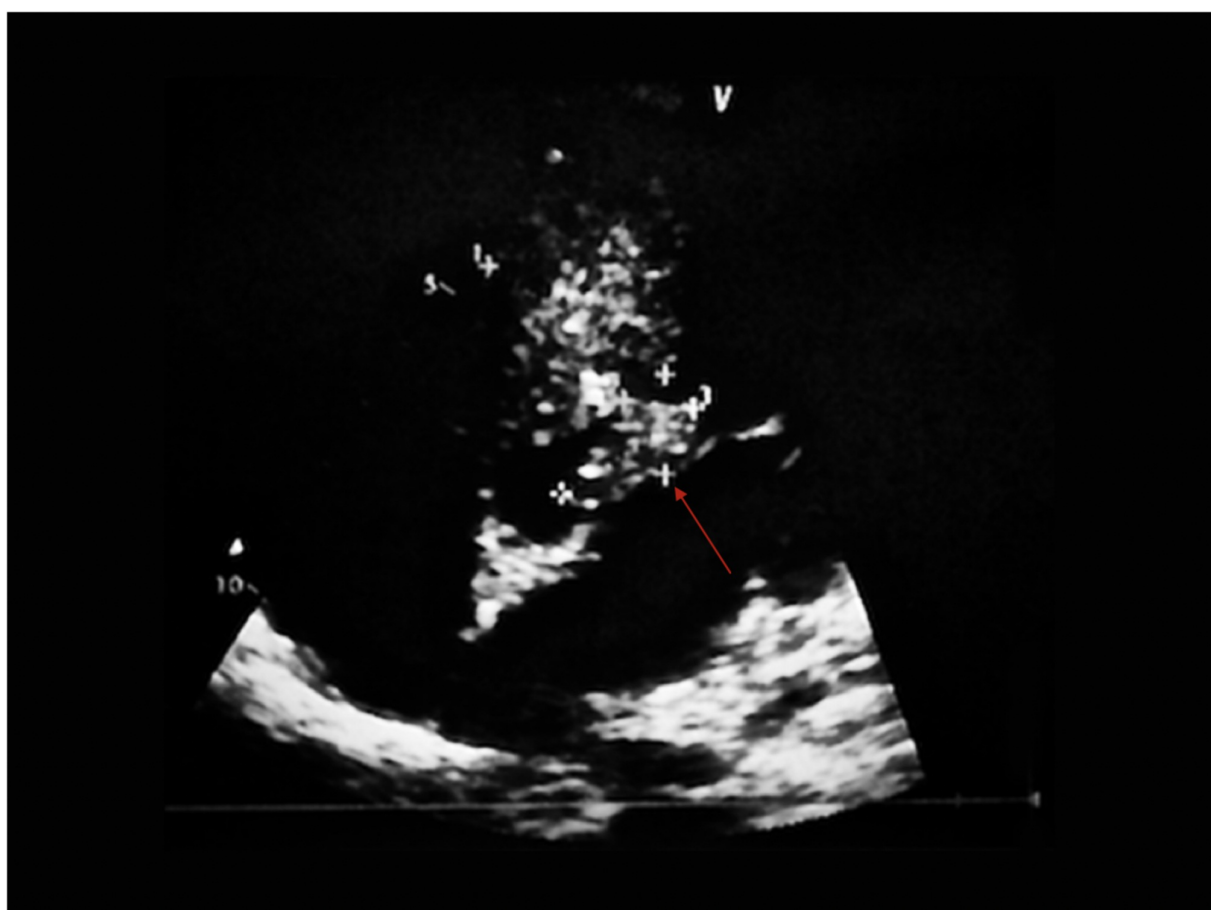

FIGURE 1: Parasternal long axis view on transthoracic echocardiogram showing a mass extending into the left ventricular outflow tract (LVOT).

There was clinical suspicion for a cardiac rhabdomyosarcoma so further imaging was obtained to delineate the mass. Cardiac MRI showed a $37 \times 45 \mathrm{~mm}$ complex irregular mass in the basal septum, growing towards both ventricles, eroding the left ventricle (LV) and further bifurcating into two linear extensions. One of the linear structures was freely mobile in the LVOT. The area of the mass in the right ventricle (RV) was

calculated at $15.5 \mathrm{~cm}^{2}$ with fronds protruding into the RV cavity. MRI findings were read as consistent with sarcoma and recommended further work with a biopsy for confirmation. The patient subsequently underwent excision of the mass and the specimen was sent for histopathology.

The patient was extubated to nasal cannula within 12 hours postoperatively. Histopathology of the tissue obtained in the operating room showed numerous septate and branching fungal hyphae which were consistent with Aspergillus species (Figure 2). Infectious disease was consulted and he was initiated on liposomal amphotericin B. On his first post-operative day, he developed an acute change in his mental status and was subsequently found to have septic embolus to his brain on MRI. The patient was made comfort measures only and passed away shortly after. 


\section{Cureus}

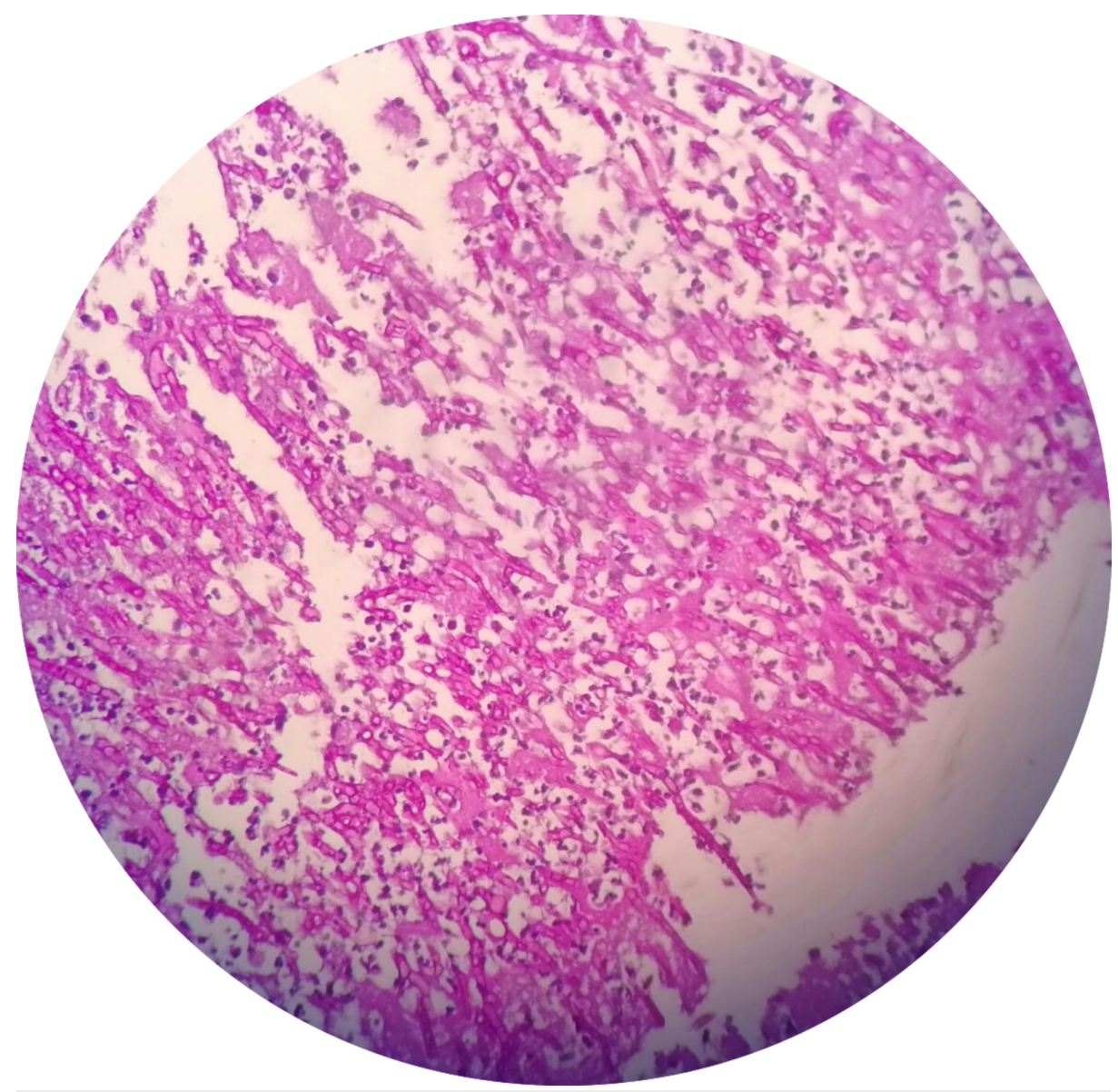

\section{FIGURE 2: Histological examination showing numerous septate and branching fungal hyphae consistent with Aspergillus species.}

\section{Discussion}

Aspergillus is a common fungus that is present in the environment and easily inhaled; however, healthy individuals have a natural immunity to the aspergillus spores. Aspergillus infections account for $0.1-3.9 \%$ of annual cases in immunocompromised patients, out of which only $0.7-6 \%$ of patients develop cardiac involvement due to the fungal infection [2]. The common predisposing risk factors of an Aspergillus infection are immunocompromised status, damaged lungs, prosthetic valves, rheumatic heart disease, longterm placement of a central venous catheter, total parenteral nutrition, and IV drug use [3-4]. Cardiac aspergilloma as presented in our case is a rare condition that is not associated with any of the above predisposing risk factors, this unique presentation is only seen in $3.4 \%$ of total cases and has not been commonly reported in literature [5].

The common etiologic agents of infective endocarditis (IE) are bacteria and fungi. Candida followed by Aspergillus are the two most common fungi responsible for fungal endocarditis [3]. Cardiac fungal infections with Aspergillus species have a high mortality rate due to the nature of the disease, difficulty in early diagnosis, and high rates of systemic embolization. In patients with aspergillus endocarditis, approximately $50 \%$ of blood cultures yield negative results as Aspergillus species is not easily detected [3]. TTE is the first diagnostic test for patients suspected of having IE with a sensitivity of $75 \%$ and specificity approaching $100 \%$. However, a negative test result does not preclude the diagnosis and a transesophageal

echocardiogram (TEE) is warranted [6]. Fungal vegetations are typically characterized as large, bulky, and highly mobile, with an increased risk of embolic events most commonly affecting the brain, as seen in our case. Cardiac MRI is a noninvasive method superior to TTE in diagnosis, differentiation, and detection of extension of cardiac masses [7]. However, the test is not always required in the diagnosis of cardiac aspergilloma. In our patient, TTE showed a large, mobile cardiac mass for which the differential diagnosis included fungal etiology, thrombus, primary cardiac tumor, myxoma, metastatic lesion, and lymphoma. In our patient, there was initial suspicion of cardiac rhabdomyosarcoma after which a cardiac MRI was obtained to further delineate the mass. Final diagnosis is best achieved by excision and biopsy of the mass. In our patient, the histologic examination revealed fungal septate hyphae confirming Aspergillus species. 


\section{Cureus}

managing patients with cardiac aspergilloma given the complexity and high mortality associated with the disease process. Most recent reviews as well as Infectious Diseases Society of America (IDSA) guidelines favor both pharmacological and surgical interventions for treatment of Aspergillus endocarditis early in the disease course to help decrease poor outcomes and mortality which include compromising cardiac function and the risk of embolic events [8]. Per IDSA, the recommended initial antifungal agents are liposomal amphotericin B or voriconazole, followed by lifelong antifungal treatment postsurgical intervention [9]. Yuan has proposed using caspofungin in addition to voriconazole and amphotericin, however, the use of combining antifungal therapies has not been shown to be superior to monotherapy $[3,9]$. In the described case, the patient underwent surgical excision of the mass and was treated with systemic liposomal amphotericin B late in his hospital course, as there was a low clinical suspicion of invasive aspergillus given his immunocompetent state. On review of the current literature, only a small number of cases of cardiac aspergilloma have previously been reported (Table 1 ) $[4,10-16]$.

\begin{tabular}{|c|c|}
\hline $\begin{array}{l}\text { Author } \\
\text { (Year) }\end{array}$ & Patient characteristics \\
\hline $\begin{array}{l}\text { Chen- } \\
\text { Milhone } \\
\text { et al. } \\
\text { (2018) [4] }\end{array}$ & $\begin{array}{l}\text { 62-year-old immunocompromised male with a past } \\
\text { medical history of prostatic adenocarcinoma on } \\
\text { chemotherapy. }\end{array}$ \\
\hline $\begin{array}{l}\text { Soman } \\
\text { et al. } \\
(2014) \\
{[10]}\end{array}$ & $\begin{array}{l}\text { 22-year-old immunocompetent male with a past } \\
\text { medical history of hepatitis B. }\end{array}$ \\
\hline $\begin{array}{l}\text { Paul et } \\
\text { al. (2012) } \\
\text { [11] }\end{array}$ & $\begin{array}{l}\text { 60-year-old female with leukemia who had } \\
\text { undergone allogeneic stem cell transplantation }\end{array}$ \\
\hline $\begin{array}{l}\text { Alvarez } \\
\text { et al. } \\
(2004) \\
{[12]}\end{array}$ & $\begin{array}{l}\text { 12-year-old female with acute lymphoblastic } \\
\text { leukemia on chemotherapy. }\end{array}$ \\
\hline $\begin{array}{l}\text { Chou et } \\
\text { al. (2013) } \\
{[13]}\end{array}$ & $\begin{array}{l}27 \text {-year-old man receiving chemotherapy for acute } \\
\text { myeloid leukemia. }\end{array}$ \\
\hline $\begin{array}{l}\text { Singla et } \\
\text { al. (2011) } \\
{[14]}\end{array}$ & $\begin{array}{l}\text { 26-year-old male with a past medical history of } \\
\text { polysubstance abuse who was being treated for } \\
\text { complications of acute pancreatitis. }\end{array}$ \\
\hline $\begin{array}{l}\text { Cishek et } \\
\text { al. (1996) } \\
\text { [15] }\end{array}$ & $\begin{array}{l}\text { 40-year-old woman with a 12-year history of severe } \\
\text { ulcerative colitis unresponsive to treatment on high } \\
\text { doses of prednisone and } 6 \text {-mercaptopurine. }\end{array}$ \\
\hline $\begin{array}{l}\text { Dang- } \\
\text { Tran et } \\
\text { al. (2014) } \\
{[16]}\end{array}$ & $\begin{array}{l}\text { 68-year-old male liver transplant patient on } \\
\text { immunosuppressive therapy. }\end{array}$ \\
\hline
\end{tabular}

Findings

Cardiac aspergilloma involving the native tricuspid valve, right atrium and ventricle.

Aspergillosis extensively involving all four chambers, the tricuspid and mitral valves of the heart.

Invasive aspergillosis of the interventricular septum.

Left ventricular pedunculated mass that was detected by echocardiographic study; at surgery, the presence of Aspergillus terreus was confirmed.

A large right ventricular mass was detected on transthoracic echocardiogram after surgical excision a specimen culture yielded Aspergillus flavus.

A large mobile tricuspid valve aspergilloma obstructing the right ventricular inlet, diagnosed incidentally on the second postoperative day after laparoscopic pancreatic abscess drainage.

Aspergillosis invading the myocardium and causing widespread necrosis and infarction.

Isolated Aspergillosis Myocardial Abscesses

TABLE 1: Review of current literature describing reported cases of cardiac aspergilloma.

Majority of the reported cases of cardiac aspergilloma have occurred in immunocompromised patients and rarely in healthy individuals as observed in our patient. In all of the cases except for one, the outcome was unfavorable resulting in the death of the patient days or weeks after diagnosis. Fungal endocarditis is associated with a mortality rate of at least $50 \%$ with an average survival period of 11 days with a $30 \%$ recurrence rate in survivors [17]. Unfortunately, our patient developed a septic embolus to his brain which ultimately led to his demise.

\section{Conclusions}

Cardiac aspergilloma is a rare disease with a high mortality rate despite aggressive pharmacological and surgical interventions. It is rarely reported in immunocompetent patients and carries a high mortality rate 
and often leads to unfavorable outcomes. Cardiac aspergilloma should remain in the differential diagnosis of cardiac masses in immunocompetent patients as early clinical suspicion will result in early treatment and decreased mortality. Survivors should be closely followed due to high recurrence rates.

\section{Additional Information \\ Disclosures}

Human subjects: Consent was obtained by all participants in this study. Conflicts of interest: In compliance with the ICMJE uniform disclosure form, all authors declare the following: Payment/services info: All authors have declared that no financial support was received from any organization for the submitted work. Financial relationships: All authors have declared that they have no financial relationships at present or within the previous three years with any organizations that might have an interest in the submitted work. Other relationships: All authors have declared that there are no other relationships or activities that could appear to have influenced the submitted work.

\section{References}

1. Tattevin P, Revest M, Lefort A, Michelet C, Lortholary O: Fungal endocarditis: current challenges. Int I Antimicrob Agents. 2014, 44:290-294. 10.1016/j.ijantimicag.2014.07.003

2. LaBarbera M, Jacobson LB: Invasive aspergillosis in an immunocompetent patient with fever and a cardiac mass. Infect Dis Rep. 2011, 3:12. 10.4081/idr.2011.e12

3. Yuan SM: Fungal endocarditis. Braz J Cardiovasc Surg. 2016, 31:252-255. 10.5935/1678-9741.20160026

4. Chen-Milhone CS, Chakravarthy Potu K, Mungee S: Cardiac aspergilloma: a rare case of a cardiac mass involving the native tricuspid valve, right atrium, and right ventricle in an immunocompromised patient. Case Rep Cardiol. 2018, 2018:4. 10.1155/2018/6927436

5. Shakoor MT, Ayub S, Ayub Z, Mahmood F: Fulminant invasive aspergillosis of the mediastinum in an immunocompetent host: a case report. J Med Case Rep. 2012, 6:311. 10.1186/1752-1947-6-311

6. Habib G, Badano L, Tribouilloy C, et al.: Recommendations for the practice of echocardiography in infective endocarditis. Eur J Echocardiogr. 2010, 11:202-219. 10.1093/ejechocard/jeq004

7. Narin B, Arman A, Arslan D, Simsek M, Narin A: Assessment of cardiac masses: magnetic resonance imaging versus transthoracic echocardiography. Anatol J Cardiol. 2010, 10:69-74.

8. Pasha AK, Lee JZ, Low SW, Desai H, Lee KS, Al Mohajer M: Fungal endocarditis: update on diagnosis and management. Am J Med. 2016, 129:1037-1043. 10.1016/j.amjmed.2016.05.012

9. Patterson TF, Thompson GR, Denning DW, et al.: Practice guidelines for the diagnosis and management of aspergillosis: 2016 update by the Infectious Diseases Society of America. Clin Infect Dis. 2016, 63:1-60. 10.1093/cid/ciw326

10. Soman SO, Vijayaraghavan G, Padmaja NP, Warrier AR, Unni M: Aspergilloma of the heart. Indian Heart J. 2014, 66:238-240. 10.1016/j.ihj.2013.12.006

11. Paul M, Schuster A, Hussain ST, Nagel E, Chiribiri A: Invasive aspergillosis: extensive cardiac involvement demonstrated by cardiac magnetic resonance. Circulation. 2012, 126:1780-1783. 10.1161/CIRCULATIONAHA.112.090852

12. Rubio Alvarez J, Sierra Quiroga J, Rubio Taboada C, Fernandez Gonzalez A, Martinon Torres F, GarciaBengochea J: Cardiac Aspergillosis with pedunculated mass in the left ventricle . Tex Heart Inst J. 2004, 31:439-441.

13. Chou HW, Chuang MK, Chen YS: Rapid recurrence of right ventricular aspergilloma . Eur J Cardiothorac Surg. 2013, 44:965. 10.1093/ejcts/ezt211

14. Singla MK, Shrivastava A, Mukherjee KC, Sodhi K: Potentially fatal tricuspid valve aspergilloma detected after laparoscopic abdominal surgery. Southern African J Anaesth Analg. 2011, 17:266-268. 10.1080/22201173.2011.10872789

15. Cishek MB, Schaefer S, Yost B: Cardiac aspergillosis presenting as myocardial infarction. Clinical Cardiol. 1996, 19:824-827. 10.1002/clc.4960191012

16. Dang-Tran K-D, Chabbert V, Esposito L, et al.: Isolated aspergillosis myocardial abscesses in a livertransplant patient. Case Rep Transplant. 2014, 2014:3. 10.1155/2014/418357

17. Ellis ME, Al-Abdely H, Sandridge A, Greer W, Ventura W: Fungal endocarditis: evidence in the world literature, 1965-1995. Clin Infect Dis. 2001, 32:50-62. 10.1086/317550 